\title{
Do sample preparation techniques affect the relative abundance of Florisphaera
}

\section{profunda?}

\author{
Lupi Claudia $^{a}$, Bordiga Manuela ${ }^{\mathrm{b}, *}$, Roberto Sacchi $^{\mathrm{a}}$, Galinetto Pietro ${ }^{\mathrm{c}}$, Beaufort Luc ${ }^{\mathrm{d}}$ and \\ Cobianchi Miriam ${ }^{\mathrm{a}}$
}

\footnotetext{
${ }^{\text {a }}$ Dipartimento di Scienze della Terra e dell'Ambiente, Università degli Studi di Pavia, Via Ferrata 9, 27100 Pavia, Italy; claudia.lupi@unipv.it; roberto.sacchi@unipv.it; miriam@unipv.it

${ }^{\mathrm{b}}$ Department of Earth Sciences, Uppsala University, Villavägen 16, 75236 Uppsala, Sweden; manuela.bordiga@geo.uu.se

${ }^{\mathrm{c}}$ Dipartimento di Fisica, Università degli Studi di Pavia, Via Bassi 6, 27100 Pavia, Italy; pietro.galinetto@unipv.it ${ }^{\mathrm{d}}$ Aix-Marseille University, CNRS, IRD, CEREGE, Avenue Louis Philibert, 13545, Aix en Provence, France; beaufort@cerege.fr
}

* Corresponding author: M. Bordiga, email: manuela.bordiga@geo.uu.se, Tel: +46 184713890

\begin{abstract}
We investigated which method among smearing, settling, filtration, and random settling is the most accurate for determining the relative abundance of Florisphaera profunda. This species is included in paleoproductivity indices because it is one of the most important deep-water dwellers. Therefore, an accurate assessment of its relative abundance is key to monitoring variations in thermocline and nutricline depths. The low birefringence and flat polygonal shape of $F$. profunda may lead to inaccurate estimates of its relative abundance as it is poorly visible under light microscopy (LM), and different sample preparation may affect the number of specimens on each slide. We studied eight samples from the Ocean Drilling Program (ODP) Site 1209B (Shatsky Rise, NW Pacific)
\end{abstract}


from the last $450 \mathrm{kyr}$. Each sample was prepared five times using each technique for a total of 160 slides. Through a rigorous analytical and statistical approach, we demonstrated the high reproducibility of each method and showed good agreement among techniques at low percentages of $F$. profunda. When the percentage of this species increases, the random settling technique differs from the others. Filtration and random settling preparation techniques were calibrated by spiking samples with microbeads. The ratio of microbeads observed in slides prepared using these two methods reflects bias due to loss of particles in the filtration technique. In addition, a hydrodynamic model for a fluttering and tumbling plate - such as $F$. profunda nannoliths - is proposed here along with calculated sinking velocities. These findings confirmed the efficiency of the long decantation time proposed for the random settling technique. The analysis of replicates, the validation with microbeads and the estimation of settling velocity of nannofossils in the tube convinced us that the higher relative abundance recorded by the random technique is not due to an imprecision of this method but, on the contrary, reflects the fact that it is more effective.

Keywords: Florisphaera profunda; preparation techniques; reliability; ANOVA 


\section{Introduction}

The extant Florisphaera profunda (Okada and Honjo, 1973) is believed a haptophyte living in the lower euphotic zone (i.e., 60-180 m, Okada and Honjo, 1973) and in waters warmer than $10^{\circ} \mathrm{C}$, as documented in the Pacific (Okada and Honjo, 1973) and Atlantic oceans (Okada and McIntyre, 1977). Regarding its taxonomy, different morphotypes are recognizable, three of which have been formally described as varieties (Quinn et al., 2005). All F. profunda morphotypes are lowbirefringence flat polygonal liths $(2-6 \mu \mathrm{m}$ in size), each consisting of a single calcite crystal; in this study we refer to $F$. profunda in a broad sense.

The occurrence of $F$. profunda is frequently considered to be indicative of primary production fluctuations and variations in thermocline and nutricline dynamics (e.g., Molfino and McIntyre, 1990; Beaufort et al., 1997; Ziveri and Thunell, 2000; Incarbona et al., 2008; Liu et al., 2008; López-Otálvaro et al., 2008). The species is directly used in paleoproductivity indices, including the PP index (Beaufort et al., 1997), the \%FP index (Beaufort et al., 2010) and the $\mathrm{N}$ ratio (Flores et al., 2000). Therefore, it is important to gather accurate data on its relative abundance within an assemblage.

The peculiar shape of $F$. profunda liths, compared to most other coccoliths, raises questions as to whether the buoyancy of flat-shaped nannoliths may influence settling and distribution on slides during the sample preparation. Haq and Lohmann (1976) argued that preparation techniques involving disaggregation and suspension of the sediment in liquids might sort coccoliths on the basis of their hydrodynamic character. Later, Stoll and Ziveri (2002) demonstrated that repeated decanting allows to separate sediment fractions, and to concentrate single nannofossil species according to their size. Hence, to exclude bias in census data, it is important to evaluate if a sample preparation method systematically produces hydrodynamic and size fractionation. This is particularly important for abundance evaluation of $F$. profunda, for which bias of identification under light microscopes (LM) could be compounded by its low birefringence.

Here, eight samples were prepared according to four commonly used and validated techniques - 
smearing (Bown and Young, 1998), settling (de Kaenel and Villa, 1996), filtration (Andruleit, 1996), and random settling (Beaufort et al., 2014) - viewed under a LM, and analyzed statistically. Additional analyses using scanning electron microscopy (SEM) have been performed to observe the particles' distribution obtained using different techniques. Recently, interest in the comparability of datasets collected using different sample preparation techniques has increased, and several studies have been carried out demonstrating that different techniques can produce significant differences in the relative and/or absolute abundances of some nannofossil species (e.g., Geisen et al., 1999; Stoll and Ziveri, 2002; Herrle and Bollmann, 2004; Henderiks and Törner, 2006; Blaj and Henderiks, 2007; Incarbona et al., 2011; Bordiga et al., 2015). For F. profunda, the influence of different preparation techniques on measurements of its abundance has never been investigated; therefore, we sought to understand the relationship between preparation method and relative abundance, and if this relationship could be explained by the morphology, buoyancy and birefringence of this species.

\section{Materials and methods}

We studied eight samples from ODP Core 1209B spanning from Marine Isotope Stage (MIS) 1 to 12 (ca. the last 450 kyr; Bordiga et al., 2013; Fig. 1). Core 1209B was collected on the Southern High of the Shatsky Rise (NW Pacific Ocean) at 2387 m water depth, above the regional lysocline (2900 m; Vincent, 1975) and calcite compensation depth (4000-4500 m; Berger and Winterer, 1974). All samples consist mainly of nannofossil ooze and nannofossil ooze with clay (Bralower et al., 2002). The carbonate content $\left(\mathrm{CaCO}_{3} \mathrm{wt} \%\right)$ ranges from 47 to $87 \%$, and ca. $50 \%$ of the carbonate component is made up of nannofossils (Bordiga et al., 2014). Details on the age model, nannofossil assemblage, preservation, paleoproductivity, and carbonate export are published in Bordiga et al. (2013; 2014).

\subsection{Sample preparation and quantitative assemblage counting}

All samples were prepared according to published smearing (Backman and Shackleton, 1983; Bown 
and Young, 1998), settling (de Kaenel and Villa, 1996), filtration (Andruleit, 1996), and random settling techniques (Beaufort et al., 2014). Details regarding laboratory materials and the protocol used for each technique are given in Appendix A.

These methods use different sediment selections and/or distributions during preparation. The smearing technique is a very common preparation method, used mostly for routine analyses, but it could produce areas with variable grain density and some size fractionation (Bown and Young, 1998). The funnel system used here for the filtration technique yields less homogeneous particle distribution compared to the in-line system as demonstrated by Bollmann et al. (2002) and by Herrle and Bollmann (2004). The settling and random settling techniques ensure a very good distribution of the suspension on the slide (de Kaenel and Villa, 1996; Beaufort et al., 2014). However, the settling and random settling methods are based on different settling times. In particular, the first method requires several steps of sinking to get rid of large particles before placement of the suspension on a cover slip, and this procedure may preferentially select particles. Each sample was replicated five times producing a set of 160 novel analyses. This number of replicates is considered sufficient for our purpose as demonstrated by previous authors (Blaj and Henderiks, 2007; Bordiga et al., 2015). All slides were analyzed for calcareous nannofossil content under LM at 1000X magnification following the taxonomic criteria reported on the website http://ina.tmsoc.org/Nannotax3 (Young et al., 2014). Approximately 300 to 1000 specimens of the total assemblages were counted. Three classes of nannofossils - F. profunda, small Noelerhabdaceae, and other coccoliths - were distinguished and their relative abundance (\%) was reported. The small Noelerhabdaceae group includes mainly Emiliania huxleyi and Gephyrocapsa spp. smaller than $4 \mu \mathrm{m}$. Species counts and percentages are given in Supplementary data.

\subsection{Independent validation using microbeads}

To supply an independent validation for the nannofossil relative abundances obtained for the same sample through different methods, the eight samples were prepared and spiked with microbeads, 
which could be considered a tracer particle as suggested by Okada (1992) and applied subsequently by Bollmann et al. (1999), Herrle and Bollmann (2004), and Bordiga et al. (2015). Because the microbeads' validation can only be used with a known weight of sediment, we could only apply it to the filtration and random settling techniques. Although beads are usually used for estimating absolute abundances of nannofossils, our attention here is focused on quantifying the beads to evaluate measurement errors of techniques when applied to samples with a priori known concentrations. For each sample, $3.1 \pm 0.04 \mathrm{mg}$ of borosilicate glass microbeads (calibrated mean diameter of $5.4 \pm 0.3 \mu \mathrm{m}$, Standard Deviation $=0.7 \mu \mathrm{m}$, density $=2.5 \mathrm{~g} / \mathrm{cm}^{3}$, SPI Supplies \#2714; www.2spi.com) were dispersed into a fixed amount of sediment $(4.1 \pm 0.06 \mathrm{mg})$. The number of beads was counted under the LM in each sample on at least 10 fields of view (FOV). The numbers of beads observed in each sample using the two techniques were subsequently converted in a filtration to random settling ratio: significant deviations from 1 indicate that the two methods do not agree in their estimates, a ratio $<1$ would indicate that filtration loses more beads than the random settling technique, and vice versa.

In addition, the eight samples prepared with filtration and spiked with beads were analyzed using SEM at 3000X magnification to verify the occurrence of differences between LM and SEM analyses. All beads encountered in 10 FOV were counted in each sample. The data were converted to a ratio between LM/SEM analyses. A ratio of 1 indicates that the two analyses are in agreement, a ratio $<1$ suggests that analysis of a filter under LM loses more beads than SEM analysis, and vice versa.

\subsection{Statistical treatment of the data}

In the past 20 years several papers have been published suggesting how the error of measurements and agreement between different techniques should be analyzed. In this paper we followed the definitions and the procedures proposed by Bland and Altman (1986), recently revisited by Bartlett and Frost (2008). The data relative to $F$. profunda and small Noelerhabdaceae were analyzed 
statistically using R ver. 3.1.0 (R Core Team, 2014). The category "other coccoliths" is a random set representing the sum of all other taxa and it is minimally informative here. Specifically, we tested:

a) the reliability of each technique, i.e., the correlation between two measurements on the same sample within each technique. The reliability evaluates the extent by which two measures on the same sample differ from each other. There are several ways to assess it, and we used: i) the magnitude of measurement error (standard deviation, SD); ii) the repeatability coefficient (r), which estimates the absolute difference between any two future measurements on the same sample; iii) the intraclass correlation coefficient (ICC), which measures the correlation between any two measurements made on the same sample using the same technique. As an estimate of the measurement errors of each technique, we use the within-subject SD from a one-way analysis of variance (ANOVA) on the repeated measurements.

b) The agreement among techniques, i.e., similarity of two measurements made on the same sample with different techniques. This was first evaluated by plotting the measurements from each technique against those from the others. If the measurements are completely free from error, we would expect the points to lie on the same diagonal line (slope=1). Significant deviations from the diagonal line are assessed by standard major axis (SMA) regressions, which assume both the dependent and independent variables do not contain any type of measurement error. Agreement among techniques was also evaluated using Bland-Altman plots, which visualize the difference in a sample measurement from two techniques against the mean of their measurements. If the measurements are free of error, the points are expected to lie on the horizontal axis, and significant deviation from this trend can be graphically assessed when points exceed the $95 \%$ limits of agreement. Significant deviations were also statistically assessed using a one-sample t-test of the mean differences, which tests the hypothesis that the true mean of the differences is zero, corresponding to no bias between the techniques.

c) The homogeneity of variances and systematic differences in sample measurements among 
techniques over the entire range of measurements. Bland-Altman plots are also used for this test. Lack of homogeneity suggests that the difference in variance among techniques may be larger when the relative abundance of calcareous nannofossils is larger, whereas homogeneity between the paired differences and the means reveals that a technique has a lower measurement error than the other one. The homogeneity of variance is statistically tested by comparing the SD of the paired technique below and above the median using a t-test. Evidence for linear associations between differences and means in Bland-Altman plots was assessed using simple linear regressions.

e) Difference in measurement errors among techniques within samples. We use a generalized least square (GLS) model, where the measurements are the dependent variable, the sample is the grouping factor and the SD is estimated for each technique. Like ANOVA, GLS models partition the variance in data into what can be ascribed to differences among groups, with the remaining variance attributed to within-group differences, but it also estimates multiple residual SDs for each group. Statistical analyses were performed using R ver. 3.1.0 (R Core Team, 2014), and otherwise stated, reported values represent means and standard errors.

\section{Results}

Florisphaera profunda percentages range between 3 and $31 \%$ in the studied samples. These data are in agreement with observations by other authors for the same area and time (Chiyonobu et al., 2012). The category small Noelerhabdaceae records very high percentages, ranging from 40 to $90 \%$ of the assemblage. This is not surprising because the studied interval encompasses the first occurrence of Emiliania huxleyi and the acme of small Gephyrocapsa caribbeanica, and it is particularly rich in small specimens of the genus Gephyrocapsa such as G. aperta, G. oceanica ( $<4$ $\mu \mathrm{m})$, G. ericsonii and G. muellerae (Lupi et al., 2012; Bordiga et al., 2013; 2014).

\subsection{Reliability of techniques between and within samples}

The general pattern of error among samples is similar across techniques, as the samples with the 
highest and lowest errors were in general the same (see panels (a) in the diagonal of Figs. 2 and 3). However, smearing and settling techniques constantly showed higher uncertainty than both filtration and random settling, which had a lower SD within samples (Table 1). Consequently, the repeatability coefficients of settling and smearing were higher than those of the other two techniques (Table 1). This means that, for example, the absolute difference between any two future measurements of $F$. profunda relative abundance are expected to be not higher than 2.31 for filtration or 4.07 for smearing method, based on $95 \%$ probability. Finally, ICCs are higher than 0.98 for all the measurements for every technique (Table 1), suggesting that more than $98 \%$ of the variability in measurements is reliably due to genuine differences in calcareous nannofossil abundances among samples, with only the remaining $2 \%$ related to errors in measurement.

\subsection{Agreement among techniques}

\subsubsection{Florisphaera profunda}

Paired plots of measured $F$. profunda relative abundances for filtration, settling and smearing techniques (see panels (b) in the left part of Fig. 2) show no significant deviations from the diagonal line of equality (slope $=1$; see Table 2 for statistics). Thus, we can infer a general agreement among these three techniques. By contrast, the estimates produced by the random settling technique are systematically higher than those of all other techniques, thus producing an increasing bias towards higher percentages of $F$. profunda. This pattern is statistically supported by SMA regression, which fits a slope significantly different from 1.0 in all comparisons (see slope values in Table 2). The Bland-Altman plots (panels (c) in the upper right part of Fig. 2) show lower agreement among techniques with some points occurring outside the 95\% agreement limits (dashed lines) in all comparisons. The lowest agreements coincide with the higher values of $F$. profunda percentages. Ttests evaluate whether the difference between measurements of the same sample using two techniques significantly deviates from zero (Table 3). No bias is evident between settling and filtration techniques (mean difference: $-0.60, \mathrm{P}=0.06$ ), while the smearing technique returns 
systematically values higher than previous two techniques (mean differences $0.95, \mathrm{P}=0.02$, and $1.55, \mathrm{P}<0.001$, respectively). However, the largest deviations are present in measurements obtained by random settling (see mean difference values in Table 3).

The variability of differences in sample measurements for each technique is not homogeneous throughout the range of measurements (see Bland-Altman plots in Fig. 2c), but the variance significantly increased with increasing percentage of $F$. profunda (see Table 4 for statistics). Consequently, the relative frequency of $F$. profunda within samples affects the errors of the techniques. In addition, Bland-Altman plots reveal correlation between random settling and all other techniques (Fig. 2), as also statistically confirmed by linear regression (absolute value of the slope > 0.66, $\mathrm{P}<0.006$; Table 4). These correlations suggest that the measurement error of the random settling technique is higher compared to all of the other techniques. The GLS model for relative abundance of $F$. profunda is highly significant $\left(\mathrm{LR}-\chi^{2}=111.92\right.$, d.f. $\left.=3, \mathrm{P}<0.0001\right)$, indicating that the measurement errors of settling, smearing and random settling are higher than that of the filtration (Table 4).

\subsubsection{Small Noelerhabdaceae}

Paired plots for the relative abundance of small Noelerhabdaceae show a general agreement among techniques (see panels (b) in the lower part of Fig. 3), and no significant deviations from the major diagonal were detected using SMA regressions (Table 2). This means that the estimates of the small Noelerhabdaceae percentage given by the four techniques are quite similar, and there is agreement among techniques for the estimate of this taxon.

The Bland-Altman plots confirm the general agreement among techniques, even though some points exceeded the $95 \%$ limits of agreements for settling when compared with both filtration and random settling techniques (see panels (c) in the higher part of Fig. 3). However, T-tests indicate a bias among these techniques, with settling providing lower estimates than the filtration and random settling techniques (see mean differences in Table 3). These tests also detect a small bias between 
filtration and smearing methods, with the former producing higher estimates (mean difference: 2.02, $\mathrm{P}=0.036$; Table 3).

The variability of the difference in sample measurements is, in general, homogeneous (Fig. 3), and only two slightly significant deviations have been detected, both involving the random settling method (Table 4). In fact, this technique has a larger SD when samples with low percentages of nannofossils are analyzed. On the other hand, Bland-Altman plots reveal clear correlations among smearing, settling and filtration, and also between random settling and smearing techniques (Fig. 3). All of these correlations are statistically supported by linear regressions (slopes $>0.23, \mathrm{P}<0.038$; Table 4), and the slopes suggest that the measurements of percentage are higher in settling than in filtration and smearing methods (Table 4). On the other hand, filtration and random settling have measurement errors higher than the smearing technique. The GLS model for relative abundance of small Noelerhabdaceae is highly significant $\left(\mathrm{LR}-\chi^{2}=54.579\right.$, d.f. $\left.=3, \mathrm{P}<0.0001\right)$, and confirms the output of the Bland-Altman plots while also showing that estimated measurement errors for smearing, settling and random settling techniques are higher than those obtained with the filtration method (Table 4).

\subsection{Validation}

The ratio between beads counted in filtration $v s$ random settling was significantly lower than 1 $\left(0.67 \pm 0.03\right.$, one sample t-test, $\left.\mathrm{t}_{7}=11.681, \mathrm{P}<0.0001\right)$, demonstrating that random settling is a more efficient preparation method than filtering (Fig. 4a). The SEM analysis allowed us to further explore the causes leading to a lower number of beads in the filters. The number of beads observed under SEM is higher than that observed under LM revealing a better performance of this technique using SEM. We can normalize the data and calculate a ratio between beads observed under LM $v s$ SEM. The LM/SEM ratio was $0.73 \pm 0.03$ and significantly differed from 1 (one-sample $\mathrm{t}$-test, $\mathrm{t}_{7}=$ 9.917, P < 0.001), demonstrating a higher accuracy when filters are analyzed under SEM (Fig. 4b). 


\section{Discussion}

4.1 Florisphaera profunda relative abundance: are reliability and agreement dependent on the preparation technique?

All preparation methods returned highly reproducible results for relative abundances with small measurement errors. The statistical analyses presented here not only confirm that the internal reproducibility of each technique is good, but it also demonstrated that data collected by different techniques are highly comparable. Nevertheless, we reported some relevant deviations among techniques concerning $F$. profunda relative abundance. For instance, slides prepared using the smearing, settling and filtration techniques and analyzed under LM retained lower percentages of $F$. profunda with respect to random settling. We can formulate some hypotheses to understand the differences in relative abundances among the four preparation techniques. They could be related to: a) the sinking time of the suspension; b) an inhomogeneous distribution of particles; c) a size selection. Smearing preparation could underestimate $F$. profunda because it might induce an inhomogeneous distribution of particles, characterized by overlapping specimens and their entrapment as indistinct aggregates. In this case, it is also possible that $F$. profunda liths are deposited at an angle that, given their optical properties, might impede their identification under LM. The filtration technique consistently gave the most accurate results, as it always provided the lowest error among replicates with respect to other techniques. However, under LM, the percentages of $F$. profunda, as well as the number of beads on filters, were consistently lower than those from random settling. Lower percentages of $F$. profunda on filters under LM have been previously reported by Incarbona et al. (2011) when compared to smear slides. They suggested that F. profunda specimens may be lost during filtration or that the smearing may enrich the samples. We minimized the loss of particles during filtration by using $47 \mathrm{~mm} \emptyset$ filters, as suggested by Bordiga et al. (2015). On the basis of our observations under both LM and SEM, we can ascribe the lower percentages to the thicker mounting medium used to make filters observable under LM, where the glue probably makes focusing more difficult. Moreover, SEM observations revealed the 
occurrence of specimens entrapped in the filter and tilted (Fig. 5). The tilted specimens of $F$. profunda are indistinguishable under LM because of its peculiar morphology and low birefringence. The arrangement of specimens is likely the main cause of the difference between the relative abundances of this species found with filtration and random settling.

The discrepancies between the percentages of $F$. profunda found through settling and random settling could be related to the coccolith sinking velocity. It is possible that some $F$. profunda specimens may be lost in the settling method. This method requires several steps of 30-90 seconds of sinking to get rid of large particles before the placement of the suspension on a cover slip. These steps may preferentially select for specific particles. On the contrary, the random settling technique systematically provided higher estimates of $F$. profunda. This technique might be more effective in quantifying the relative abundance of $F$. profunda under LM because it is based on a fixed decantation time for the entire suspension. Applying Stokes' law, the settling velocity of a coccolith is assessed by using an ideal sphere with the same volume of the real particle, but $F$. profunda can be considered as a two dimensional object. Flat, thin plates generally settle more slowly than their equivalent spheres. A proper parameter can be used to take into account the deviation from a high symmetry object. By modifying Stokes' law, we obtained a value of $0.003 \mathrm{~mm} / \mathrm{s}$ for sinking velocity (see Supplementary material for details and sinking velocity calculation). This value could be further decreased considering the fluttering of a thin plate (Andersen et al., 2005). This phenomenon introduces a non-negligible horizontal component in the sinking velocity vector with a reduction of the sinking value by a factor of four or more (Supplementary material). In the settling technique, from our estimated sinking velocities, small coccoliths and $F$. profunda could sink ca. 0.06 to $0.5 \mathrm{~cm}$ within 90 seconds, and thus, some selection of the specimens could occur during preparation. To account for this, Beaufort et al. (2014) use a buffered water column with thickness of $1 \mathrm{~cm}$ and wait for four hours before mounting the slide to ensure the deposition of all particles.

\section{Concluding Remarks}


The main aim of this paper is to investigate whether the relative abundance of $F$. profunda is affected by preparation technique and/or species morphology. A total of 160 slides were statistically analyzed to answer this question. We considered four standard preparation techniques (smearing, settling, filtration and random settling) preparing, for each method, eight samples five times. Our findings demonstrate that the four techniques give highly reproducible data with regard to relative abundances of all categories considered here. However, it is clear that, at low percentages of $F$. profunda, all techniques produce very similar results, but that when the percentage increases the random settling technique differs from the others.

The analysis of replicates, the validation with microbeads and the estimation of settling velocity of nannofossils convinced us that the higher percentage recorded by the random technique is not due to an imprecision of this method but, on the contrary, reflects the fact that it is more effective in providing a good distribution and orientation of particles. Indeed, our detailed SEM analyses on filters demonstrated that particles are not always flat on the filter and small coccoliths are entrapped in the filter and/or tilted. Under LM, this behavior combined with the need to use a considerable amount of glue to make the filter transparent could limit the identification of small coccoliths and $F$. profunda. Therefore, the lower $F$. profunda abundances recorded under LM from smearing, settling and filtration can be attributed to particle selection/distribution during preparation or to the mounting medium for filtration. The random settling technique seems to generate estimations that are more accurate under LM, as the preparation time permits the settling of all particles in the suspension which is particularly important for plates that have peculiar trajectory and need a longer time to settle.

However, the relative abundances derived from the random settling show systematic differences which are closer to the "real" values, as demonstrated by the calibration with microbeads. Consequently, percentage data obtained with each of the four methods are consistent, and values obtained with smearing, settling and filtration can be compared, but these values have to be carefully compared with values obtained by the random settling. 


\section{Figure captions}

Figure 1. A. Location map of ODP Site 1209 on the Shatsky Rise (modified from Kawahata and Ohshima, 2002).

Figure 2. Pairwise comparison among techniques applied to $F$. profunda. Panels (a) on the diagonal report the percentages together with the measurement errors (standard deviations and $95 \%$ confidence intervals) of each technique for the eight samples. Panels (b) plot the measurements from each technique against those from the others; the solid line is the diagonal line of equality (slope $=1)$ expected in case of perfect agreement between techniques; the dotted line is the observed pattern as found by standard major axis regressions. Panels (c) report Bland-Altman plots, which visualize the difference in a sample measurement from two techniques against the mean of their measurements; dotted lines are the $95 \%$ limits of agreement. The symbols represent the eight studied samples.

Figure 3. Pairwise comparison among techniques applied to small Noelerhabdaceae. Panels (a) on the diagonal report the percentages together with the measurement errors (standard deviations and 95\% confidence intervals) of each technique for the eight samples. Panels (b) plot the measurements from each technique against those from the others; the solid line is the diagonal line of equality (slope $=1$ ) expected in case of perfect agreement between techniques; the dotted line is the observed pattern as found by standard major axis regressions. Panels (c) report Bland-Altman plots, which visualize the difference in a sample measurement from two techniques against the mean of their measurements; dotted lines are the $95 \%$ limits of agreement. The symbols represent the eight studied samples.

Figure 4. Ratios between beads counted for each sample in (a) filtration vs random settling, and (b) 
LM vs SEM. See methods for details.

Figure 5. SEM photographs collected on filter (4.5 mbsf): a. the arrows indicate small coccoliths tilted (3000X); b. the arrows indicate small coccoliths entrapped into the filter; c. the arrows indicate specimens of $F$. profunda tilted. Scale bar $=10 \mu \mathrm{m}$.

\section{Table captions}

Table 1. Standard deviation (SD) between samples ( $\left.\mathrm{SD}_{\text {between }}\right)$, measurement error $\left(\mathrm{SD}_{\text {within }}\right)$, repeatability coefficient ( $r$, which estimates the absolute difference between any two future measurements on the same sample), and intraclass correlation coefficient (ICC, which measures the correlation between any two measurements made on the same sample using the same technique), for the four techniques (smearing, settling, filtration, and random settling) applied to the assessment of the same eight samples with five replicates of $F$. profunda and small Noelerhabdaceae. All of the values in brackets represent the $95 \%$ confidence interval (CI95\%).

Table 2. Slope (estimated using SMA regression) and deviation from the major diagonal of measurements from each technique against those from others for the same samples (see methods for details). Significant deviations of slopes from $1(\mathrm{P}<0.05)$ indicate lack of agreement between techniques.

Table 3. Deviation from zero (t-test) of the difference in measurements from two techniques applied to the same sample; Diff. is the difference between the estimates of two techniques, values in brackets represent the $95 \%$ confidence interval (CI95\%) for the estimated differences, $\mathrm{t}_{39}$ are the statistics for the t-test, and significant results $(\mathrm{P}<0.05)$ indicate lack of agreement between techniques. 
Table 4. T-tests for the homogeneity of variances and linear regressions for the association between differences and means in Bland-Altman plots.

Appendix A. Material used for sample preparations and method protocols.

Supplementary material is provided in a .pptx format.

\section{Acknowledgments}

The authors are grateful to the International Ocean Discovery Program (IODP) core repository in Kochi (Japan) for providing samples to M.C. for this research. The ODP (now IODP) was sponsored by the US National Science Foundation and participating countries under management of the Joint Oceanographic Institutions (JOI), Inc. We especially thank the Editor F.J. Jorissen which encouraged us to improve the paper, and the two anonymous reviewers for providing constructive comments. This study incorporates results of the Ph.D. Thesis of M.B. The project was financially supported by the University of Pavia Grant (FARG-2014) to CL, and by the Swedish Research Council of Uppsala University (VR grant 2011-4866 to Jorijntje Henderiks). We thank Miloš Bartol for his assistance with the SEM setup (at Uppsala University) and Jorijntje Henderiks for providing the lab material.

\section{Author contributions}

C.L. and M.B contributed equally to the preparation of this manuscript. R.S. performed the statistics, and P.G. the physical model for the sinking of coccoliths. M.C. and L.B. supervised and edited the manuscript.

\section{References}

Andersen, A., Pesavento, U., Wang, Z.J., 2005. Unsteady aerodynamics of fluttering and tumbling 
plates. J. Fluid Mech. 541, 65-90.

Andruleit, H., 1996. A filtration technique for quantitative studies of coccoliths. Micropaleontology 42, 403-406.

Backman, J., Shackleton, N.J., 1983. Quantitative biochronology of Pliocene and early Pleistocene calcareous nannofossils from Atlantic, Indian and Pacific oceans. Mar. Micropaleontol. 8, $141-170$.

Bartlett, J.W., Frost, C., 2008. Reliability, repeatability and reproducibility: analysis of measurements errors in continuous variables. Ultrasound Obst. Gyn. 31, 466-475.

Beaufort, L., Lancelot, Y., Camberin, P., Cayre, O., Vincent, E., Bassinot, F., Labeyrie, L., 1997. Insolation cycles as a major control of Equatorial Indian Ocean Primary Productivity. Science $278,1451-1454$.

Beaufort, L., van der Kaars, S., Bassinot, F.C., Moron, V., 2010. Past dynamics of the Australian monsoon: precession, phase and links to the global monsoon concept. Clim. Past 6, 695-706.

Beaufort, L., Barbarin, N., Gally, Y., 2014. Optical measurements to determine the thickness of calcite crystals and the mass of thin carbonate particles such as coccoliths. Nature Protocols 9 (3), 633-642. http://dx.doi.org/10.1038/nprot.2014.028.

Berger, W.H., Winterer, E.L., 1974. Plate stratigraphy and the fluctuating carbonate line. In: Hsü, K.J., Jenkyns, H.C. (Eds.), Pelagic Sediment: on Land and under the Sea, International Sedimentologists Special Publication 1, Blackwell Publishing Ltd., Oxford, UK, pp. 11-48.

Blaj, T., Henderiks, J., 2007. Smear and spray preparation techniques put to the test (II): reproducibility and accuracy of calcareous nannofossil assemblage counts. J. Nannoplankton Res. 29, 92-100.

Bland, J.M., Altman, D.G., 1986. Statistical methods for assessing agreement between two methods of clinical measurement. The Lancet 327 (8476), 307-310.

Bollmann, J., Brabec, B., Cortes, M., Geisen, M., 1999. Determination of abso-lute coccolith abundances in deep-sea sediments by spiking with microbeadsand spraying (SMS method). 
Mar. Micropaleontol. 38, 29-38.

Bollmann, J., Cortés M.Y., Haidar A.T., Brabec B., Close A., Hofmann R., Palma S., Tupas L., Thierstein H.R., 2002. Techniques for quantitative analyses of calcareous marine phytoplankton. Mar. Micropaleontol. 4(3), 163-185.

Bordiga, M., Beaufort, L., Cobianchi, M., Lupi, C., Mancin, N., Luciani, V., Pelosi, N., Sprovieri, M., 2013. Calcareous nannofossils as dissolution and primary productivity proxies in the last 450 ka (Shatsky Rise, NW Pacific Ocean). Palaeogeogr. Palaeoclimatol. Palaeoecol. 371, 93108.

Bordiga, M., Cobianchi, M., Lupi, C., Pelosi, N., Venti, N.L., Ziveri, P., 2014. Coccolithophore carbonate during the last $450 \mathrm{ka}$ in the NW Pacific Ocean (ODP Site 1209B, Shatsky Rise). J. Quaternary Sci. 29, 57-69.

Bordiga, M., Bartol, M., Henderiks, J., 2015. Absolute nannofossil abundance estimates: Quantifying the pros and cons of different techniques. Revue de micropaléontologie. http://dx.doi.org/10.1016/j.revmic.2015.05.002.

Bown, P.R., Young, J.R., 1998. Techniques. In: Bown, P.R. (Ed.), Calcareous Nannofossil Biostratigraphy. Chapman \& Hall, Cambridge, pp. 16-28.

Bralower, T.J, Premoli Silva, I., Malone, M.J., et al., 2002. Site 1209. Proceedings of the Ocean Drilling Program, Initial Reports 198, College Station, TX, pp. 1-102.

Chiyonobu, S., Mori, Y., Oda, M., 2012. Reconstruction of paleoceanographic conditions in the northwestern Pacific Ocean over the last 500 kyr based on calcareous nannofossil and planktic foraminiferal assemblages. Mar. Micropaleontol. 96-97, 29-37.

de Kaenel, E., Villa, G., 1996. Oligocene-Miocene calcareous nannofossil biostratigraphy and paleoecology from the Iberia Abyssal Plain. In: Whitmarsh, R.B., Sawyer, D.S., Klaus, A., Masson, D.G. (Eds.), Proceeding of the Ocean Drilling Program, Scientific Results 149, College Station, TX, pp. 79-145.

Flores, J.A., Gersonde, R., Sierro, F.J., Niebler, H.S., 2000. Southern Pleistocene calcareous 
nannofossil events. Calibrations with isotope and geomagnetic stratigraphies. Mar. Micropaleontol. 40, 377-402.

Geisen, M., Bollmann, J., Herrle, J.O., Mutterlose, J., Young, J.R., 1999. Calibration of the random settling technique for calculation of absolute abundances of calcareous nannoplankton. Micropaleontology 45, 437-442.

Haq, B.U., Lohmann, G.P., 1976. Early Cenozoic calcareous nannoplankton biogeography of the Atlantic Ocean. Mar. Micropaleontol. 1, 119-194.

Henderiks, J., Törner, A., 2006. Reproducibility of coccolith morphometry: evaluation of spraying and smear slide preparation techniques. Mar. Micropaleontol. 58, 207-218.

Herrle, J.O., Bollmann, J., 2004. Accuracy and reproducibility of absolute nannoplankton abundances using the filtration technique in combination with a rotary sample splitter. Mar. Micropaleontol. 53, 389-404.

Incarbona, A., Bonomo, S., Di Stefano, E., Zgozi, S., Essarbout, N., Talha, M., Tranchida, G., Bonanno, A., Patti, B., Placenti, F., Buscaino, G., Cuttitta, A., Basilone, G., Bahri, T., Massa, F., Censi, P., Mazzola, S., 2008. Calcareous nannofossil surface sediment assemblages from the Sicily Channel (central Mediterranean Sea): palaeoceanographic implications. Mar. Micropaleontol. 67, 297-309.

Incarbona, A., Ziveri, P., Sabatino, N., Salvagio Manta, D., Sprovieri, M., 2011. Conflicting coccolithophore and geochemical evidence for productivity levels in the Eastern Mediterranean Sapropel S1. Mar. Micropaleontol. 81, 131-143.

Kawahata, H., Ohshima, H., 2002. Small latitudinal shift in the Kuroshio Extension (Central Pacific) during glacial times: evidence from pollen transport. Quaternary Sci. Rev. 21, 17051717.

Liu, C.L., Wang, P.X., Tian, J., Cheng, X.R., 2008. Coccolith evidence for Quaternary nutricline variations in the southern South China Sea. Mar. Micropaleontol. 69, 42-51. 
López-Otálvaro, G.-E., Flores, J.-A., Sierro, F.J., Cacho, I., 2008. Variations in coccolithophorid production in the Eastern Equatorial Pacific at ODP Site 1240 over the last seven glacialinterglacial cycles. Mar. Micropaleontol. 69, 52-69.

Lupi, C., Bordiga, M., Cobianchi, M., 2012. Gephyrocapsa occurrence during the Middle Pleistocene Transition in the Northern Pacific Ocean (Shatsky Rise). Geobios 45, 209-217.

Molfino, B., McIntyre, A., 1990. Nutricline variation in the equatorial Atlantic coincident with the Younger Dryas. Paleoceanography 5, 997-1008. http://dx.doi.org/10.1029/PA005i006p00997.

Okada, H., 1992. Use of microbeads to estimate the absolute abundance of nannofossils. INA Newsletter, 14, 96-97.

Okada, H., Honjo, S., 1973. The distribution of oceanic coccolithophorids in the Pacific. Deep-Sea Research and Oceanographic Abstracts 20 (4), 355-374.

Okada, H., McIntyre, A., 1977. Modern coccolithophores of the Pacific and North Atlantic Oceans. Micropaleontology 23, 1-55.

Quinn, P.S., Cortés, M.Y., Bollmann, J., 2005. Morphological variation in the deep ocean-dwelling coccolithophore Florisphaera profunda (Haptophyta). Eur. J. Phycol. 40 (1), 123-133.

R Core Team, 2014. R: A language and environment for statistical computing. R Foundation for Statistical Computing, URL: http://www.R-project.org/, Vienna.

Stoll, H.M., Ziveri, P., 2002. Separation of monospecific and restricted coccolith assemblages from sediments using differential settling velocity. Mar. Micropaleontol. 46, 209-221.

Vincent, E., 1975. Neogene Planktonic Foraminifera from the central north pacific, leg 32, Deep Sea Drilling Project. In: Larson, R.L., Moberly, R., et al. (Eds.), Initial Reports of the Deep Sea Drilling Project 32, Washington, (U.S. Government Printing Office), pp. 765-801.

Young, J. R., Bown P.R., Lees, J. A. 2014. Nannotax3 website. International Nannoplankton Association. 21 Apr. 2014. URL: http://http://ina.tmsoc.org/Nannotax3. 
Ziveri, P., Thunell, R.C., 2000. Coccolithophores export production in Guaymas Basin, Gulf of California: response to climatic forcing. Deep-Sea Res. Pt. II 47, 2073-2100. 
Table 1

\begin{tabular}{|c|c|c|c|}
\hline & & Florisphaera profunda & $\begin{array}{c}\text { Small } \\
\text { Noelerhabdaceae }\end{array}$ \\
\hline \multicolumn{4}{|l|}{ SD } \\
\hline \multirow{2}{*}{ Smearing } & between & $10.39(7.79-21.15)$ & $25.94(19.46-52.81)$ \\
\hline & within & $1.47(0.87-1.89)$ & $2.33(1.39-2.99)$ \\
\hline \multirow{2}{*}{ Settling } & between & $11.8(8.85-24.02)$ & $44.08(33.07-89.72)$ \\
\hline & within & $1.32(0.78-1.69)$ & $2.54(1.51-3.27)$ \\
\hline \multirow{2}{*}{ Filtration } & between & $10.47(7.85-21.31)$ & $36.47(27.36-74.23)$ \\
\hline & within & $0.83(0.50-1.07)$ & $1.50(0.89-1.92)$ \\
\hline \multirow{2}{*}{ Random } & between & $21.22(15.92-43.2)$ & $34.7(26.03-70.63)$ \\
\hline & within & $1.14(0.68-1.46)$ & $1.61(0.96-2.07)$ \\
\hline \multicolumn{4}{|l|}{$\mathbf{r}$} \\
\hline Smearing & & $4.07(2.42-5.23)$ & $6.46(3.84-8.29)$ \\
\hline Settling & & $3.65(2.17-4.68)$ & $7.05(4.19-9.05)$ \\
\hline Filtration & & $2.31(1.38-2.97)$ & $4.15(2.47-5.32)$ \\
\hline Random & & $3.15(1.87-4.04)$ & $4.47(2.66-5.74)$ \\
\hline \multicolumn{4}{|l|}{ ICC } \\
\hline Smearing & & $0.980(0.897-0.991)$ & $0.992(0.957-0.996)$ \\
\hline Settling & & $0.988(0.935-0.994)$ & $0.997(0.982-0.998)$ \\
\hline Filtration & & $0.994(0.966-0.997)$ & $0.998(0.991-0.999)$ \\
\hline Random & & $0.997(0.985-0.999)$ & $0.998(0.988-0.999)$ \\
\hline
\end{tabular}


Table 2

\begin{tabular}{lcccc} 
& Slope & CI95\% & r & P \\
\hline Florisphaera profunda & & & & \\
Random vs Filtration & 1.84 & $1.55-2.18$ & 0.96 & $<0.001$ \\
Settling vs Filtration & 1.1 & $0.97-1.24$ & 0.56 & 0.14 \\
Settling vs Random & 0.6 & $0.50-0.71$ & -0.94 & $<0.001$ \\
Smearing vs Filtration & 1.16 & $0.95-1.42$ & 0.55 & 0.15 \\
Smearing vs Random & 0.63 & $0.49-0.82$ & -0.85 & 0.0052 \\
Smearing vs Settling & 1.06 & $0.88-1.27$ & 0.27 & 0.51 \\
\hline & & & & \\
Small Noelerhabdaceae & & & & \\
Random vs Filtration & 1 & $0.96-1.03$ & -0.09 & 0.83 \\
Settling vs Filtration & 0.95 & $0.90-1.00$ & -0.64 & 0.08 \\
Settling vs Random & 0.95 & $0.88-1.03$ & -0.47 & 0.24 \\
Smearing vs Filtration & 0.97 & $0.91-1.02$ & -0.49 & 0.21 \\
Smearing vs Random & 0.97 & $0.92-1.02$ & -0.45 & 0.25 \\
Smearing vs Settling & 1.02 & $0.91-1.13$ & 0.13 & 0.76 \\
\hline
\end{tabular}

Table 3

\begin{tabular}{lcccc} 
& Diff & CI95\% & $\mathbf{t}_{\mathbf{3 9}}$ & P \\
\hline Florisphaera profunda & & & & \\
Filtration vs Random & -5.19 & $-6.84--3.53$ & -6.346 & $<0.001$ \\
Filtration vs Settling & -0.6 & $-1.21-0.01$ & -1.981 & 0.06 \\
Filtration vs Smearing & -1.55 & $-2.28--0.82$ & -4.299 & $<0.001$ \\
Random vs Settling & 4.59 & $3.06-6.11$ & 6.058 & $<0.001$ \\
Random vs Smearing & 3.64 & $1.80-5.46$ & 4.016 & $<0.001$ \\
Settling vs Smearing & -0.95 & -1.59 & -2.427 & 0.02 \\
\hline & & & & \\
Small Noelerhabdaceae & & & & \\
Filtration vs Random & 0.16 & $-1.03-1.34$ & 0.265 & 0.79 \\
Filtration vs Settling & 4.71 & $3.24-6.19$ & 6.475 & $<0.001$ \\
Filtration vs Smearing & 2.02 & $0.13-3.91$ & 2.166 & 0.036 \\
Random vs Settling & 4.56 & $2.40-6.72$ & 4.273 & $<0.001$ \\
Random vs Smearing & 1.87 & $0.01-3.73$ & 2.207 & 0.05 \\
Settling vs Smearing & -2.69 & $-5.64-0.26$ & -1.845 & 0.073 \\
\hline
\end{tabular}


Table 4

\begin{tabular}{|c|c|c|c|c|c|c|}
\hline & \multicolumn{3}{|c|}{ SD homogeneity } & \multicolumn{3}{|c|}{ Association } \\
\hline & Difference & $\mathbf{t}$ & $\mathbf{P}$ & slope & CI95\% & $\mathbf{P}$ \\
\hline \multicolumn{7}{|l|}{$\begin{array}{l}\text { Florisphaera } \\
\text { profunda }\end{array}$} \\
\hline Filtration vs Random & $3.62,5.58$ & 3.904 & 0.005 & -0.75 & $-0.52--1.09$ & 0.001 \\
\hline Filtration vs Settling & $0.85,2.41$ & 2.965 & 0.05 & -0.28 & $-0.13--0.64$ & 0.29 \\
\hline $\begin{array}{l}\text { Filtration vs } \\
\text { Smearing }\end{array}$ & $1.17,3.07$ & 4.119 & 0.014 & -0.43 & $-0.18--1.05$ & 0.97 \\
\hline Random vs Settling & $3.63,4.65$ & 3.096 & 0.015 & 0.66 & $0.42-1.03$ & 0.003 \\
\hline Random vs Smearing & $3.63,5.94$ & 4.244 & 0.003 & 0.84 & $0.51-1.36$ & 0.006 \\
\hline Settling vs Smearing & $1.21,2.99$ & 3.442 & 0.015 & 0.37 & $0.16-0.86$ & 0.39 \\
\hline
\end{tabular}

\section{Small}

Noelerhabdaceae

Filtration vs Random

Filtration vs Settling

Filtration vs

Smearing

Random vs Settling

Random vs Smearing

Settling vs Smearing

$$
4.11,2.31
$$

2.599

0.034

0.22

$0.09-0.52$

0.58

$3.04,1.79$

1.641

0.16

$-0.23$

$-0.13--0.38$

0.010

4.16, 3.74

0.454

0.67

0.4

$0.24-0.66$

0.007

$4.13,3.24$

1.225

0.26

$-0.39$

$-0.19--0.79$

0.094

7.00, 4.07

2.897

0.02

0.4

$0.21-0.76$

0.038

$$
\text { 4.56, } 4.88
$$

0.247

0.81

0.6

$0.38-0.96$

0.004 
Florisphaera profunda

\begin{tabular}{|c|c|c|c|}
\hline \multirow{2}{*}{\multicolumn{4}{|c|}{ voeiernabaaceae }} \\
\hline & & & \\
\hline \multirow{2}{*}{ Smearing } & between & $10.39(7.79-21.15)$ & $25.94(19.46-52.81)$ \\
\hline & within & $1.47(0.87-1.89)$ & $2.33(1.39-2.99)$ \\
\hline \multirow{2}{*}{ Settling } & between & $11.8(8.85-24.02)$ & $44.08(33.07-89.72)$ \\
\hline & within & $1.32(0.78-1.69)$ & $2.54(1.51-3.27)$ \\
\hline \multirow{2}{*}{ Filtration } & between & $10.47(7.85-21.31)$ & $36.47(27.36-74.23)$ \\
\hline & within & $0.83(0.50-1.07)$ & $1.50(0.89-1.92)$ \\
\hline \multirow{2}{*}{ Random } & between & $21.22(15.92-43.2)$ & $34.7(26.03-70.63)$ \\
\hline & within & $1.14(0.68-1.46)$ & $1.61(0.96-2.07)$ \\
\hline \multicolumn{4}{|l|}{$\mathbf{r}$} \\
\hline Smearing & & $4.07(2.42-5.23)$ & $6.46(3.84-8.29)$ \\
\hline Settling & & $3.65(2.17-4.68)$ & $7.05(4.19-9.05)$ \\
\hline Filtration & & $2.31(1.38-2.97)$ & $4.15(2.47-5.32)$ \\
\hline Random & & $3.15(1.87-4.04)$ & $4.47(2.66-5.74)$ \\
\hline \multicolumn{4}{|l|}{ ICC } \\
\hline Smearing & & $0.980(0.897-0.991)$ & $0.992(0.957-0.996)$ \\
\hline Settling & & $0.988(0.935-0.994)$ & $0.997(0.982-0.998)$ \\
\hline Filtration & & $0.994(0.966-0.997)$ & $0.998(0.991-0.999)$ \\
\hline Random & & $0.997(0.985-0.999)$ & $0.998(0.988-0.999)$ \\
\hline
\end{tabular}




\begin{tabular}{lcccc} 
& Slope & CI95\% & r & P \\
\hline Florisphaera profunda & & & & \\
Random vs Filtration & 1.84 & $1.55-2.18$ & 0.96 & $<0.001$ \\
Settling vs Filtration & 1.1 & $0.97-1.24$ & 0.56 & 0.14 \\
Settling vs Random & 0.6 & $0.50-0.71$ & -0.94 & $<0.001$ \\
Smearing vs Filtration & 1.16 & $0.95-1.42$ & 0.55 & 0.15 \\
Smearing vs Random & 0.63 & $0.49-0.82$ & -0.85 & 0.0052 \\
Smearing vs Settling & 1.06 & $0.88-1.27$ & 0.27 & 0.51 \\
\hline
\end{tabular}

Small Noelerhabdaceae

Random vs Filtration

Settling vs Filtration

\begin{tabular}{cccc}
1 & $0.96-1.03$ & -0.09 & 0.83 \\
0.95 & $0.90-1.00$ & -0.64 & 0.08 \\
0.95 & $0.88-1.03$ & -0.47 & 0.24 \\
0.97 & $0.91-1.02$ & -0.49 & 0.21 \\
0.97 & $0.92-1.02$ & -0.45 & 0.25 \\
1.02 & $0.91-1.13$ & 0.13 & 0.76 \\
\hline
\end{tabular}

Settling vs Random

Smearing vs Filtration

Smearing vs Random

Smearing vs Settling

\section{Table 3}

\begin{tabular}{lcccc} 
& Diff & CI95\% & $\mathbf{t}_{\mathbf{3 9}}$ & P \\
\hline Florisphaera profunda & & & & \\
Filtration vs Random & -5.19 & $-6.84--3.53$ & -6.346 & $<0.001$ \\
Filtration vs Settling & -0.6 & $-1.21-0.01$ & -1.981 & 0.06 \\
Filtration vs Smearing & -1.55 & $-2.28--0.82$ & -4.299 & $<0.001$ \\
Random vs Settling & 4.59 & $3.06-6.11$ & 6.058 & $<0.001$ \\
Random vs Smearing & 3.64 & $1.80-5.46$ & 4.016 & $<0.001$ \\
Settling vs Smearing & -0.95 & -1.59 & -2.427 & 0.02 \\
\hline
\end{tabular}

\section{Small Noelerhabdaceae}

Filtration vs Random

$$
0.16
$$

$$
-1.03-1.34
$$

0.265

0.79

Filtration vs Settling

$3.24-6.19$

6.475

$<0.001$

Filtration vs Smearing

$0.13-3.91$

2.166

0.036

Random vs Settling

4.56

$2.40-6.72$

4.273

$<0.001$

Random vs Smearing

1.87

$0.01-3.73$

2.207

0.05

Settling vs Smearing

$-2.69 \quad-5.64-0.26$

$-1.845$

0.073




\begin{tabular}{|c|c|c|c|c|c|c|}
\hline & \multicolumn{3}{|c|}{ SD homogeneity } & \multicolumn{3}{|c|}{ Association } \\
\hline & Difference & $\mathbf{t}$ & $\mathbf{P}$ & slope & CI95\% & $\mathbf{P}$ \\
\hline \multicolumn{7}{|l|}{$\begin{array}{l}\text { Florisphaera } \\
\text { profunda }\end{array}$} \\
\hline Filtration vs Random & $3.62,5.58$ & 3.904 & 0.005 & -0.75 & $-0.52--1.09$ & 0.001 \\
\hline Filtration vs Settling & $0.85,2.41$ & 2.965 & 0.05 & -0.28 & $-0.13--0.64$ & 0.29 \\
\hline $\begin{array}{l}\text { Filtration vs } \\
\text { Smearing }\end{array}$ & $1.17,3.07$ & 4.119 & 0.014 & -0.43 & $-0.18--1.05$ & 0.97 \\
\hline Random vs Settling & $3.63,4.65$ & 3.096 & 0.015 & 0.66 & $0.42-1.03$ & 0.003 \\
\hline Random vs Smearing & $3.63,5.94$ & 4.244 & 0.003 & 0.84 & $0.51-1.36$ & 0.006 \\
\hline Settling vs Smearing & $1.21,2.99$ & 3.442 & 0.015 & 0.37 & $0.16-0.86$ & 0.39 \\
\hline \multicolumn{7}{|l|}{$\begin{array}{l}\text { Small } \\
\text { Noelerhabdaceae }\end{array}$} \\
\hline Filtration vs Random & $4.11,2.31$ & 2.599 & 0.034 & 0.22 & $0.09-0.52$ & 0.58 \\
\hline Filtration vs Settling & $3.04,1.79$ & 1.641 & 0.16 & -0.23 & $-0.13--0.38$ & 0.010 \\
\hline $\begin{array}{l}\text { Filtration vs } \\
\text { Smearing }\end{array}$ & $4.16,3.74$ & 0.454 & 0.67 & 0.4 & $0.24-0.66$ & 0.007 \\
\hline Random vs Settling & $4.13,3.24$ & 1.225 & 0.26 & -0.39 & $-0.19--0.79$ & 0.094 \\
\hline Random vs Smearing & $7.00,4.07$ & 2.897 & 0.02 & 0.4 & $0.21-0.76$ & 0.038 \\
\hline Settling vs Smearing & $4.56,4.88$ & 0.247 & 0.81 & 0.6 & $0.38-0.96$ & 0.004 \\
\hline
\end{tabular}


Figure 1

Fig. 1 - Lupi et al. (1.5 column)

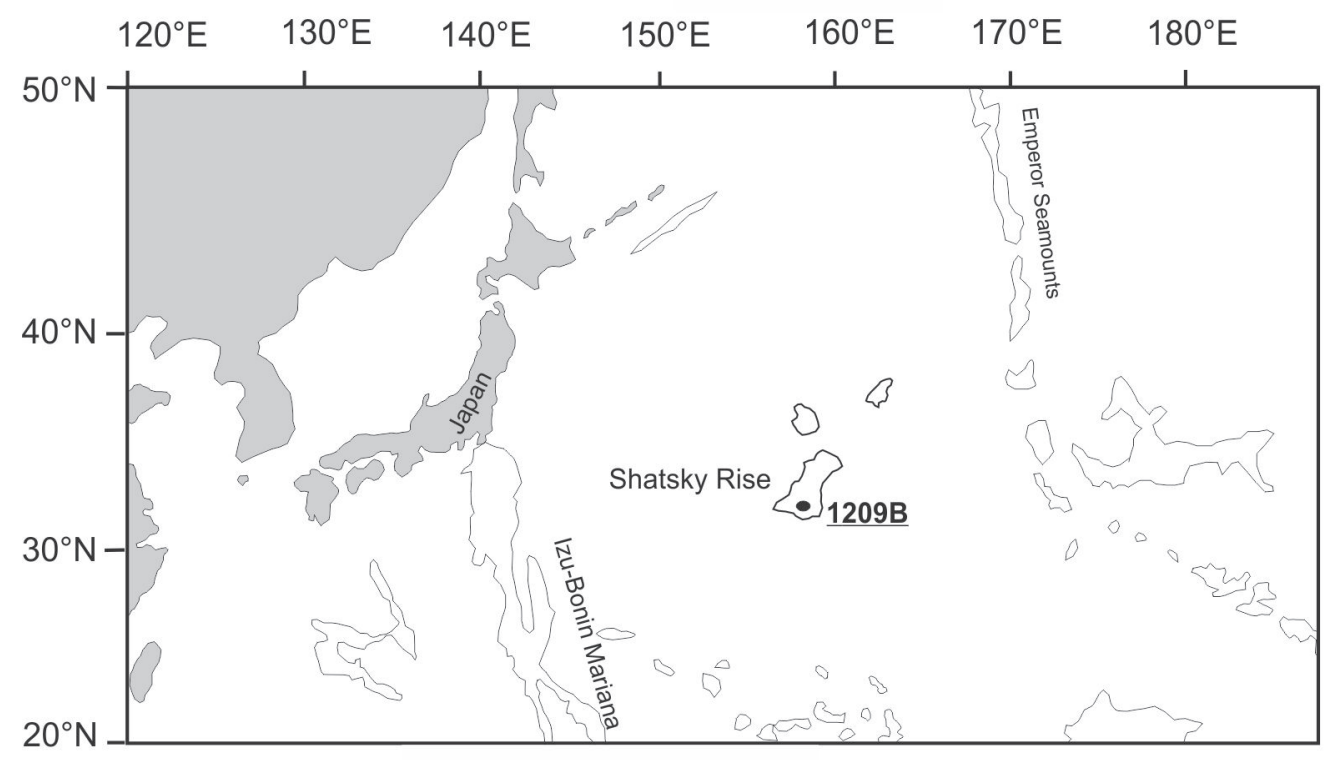


Fig. 2 - Lupi et al. (2 columns)
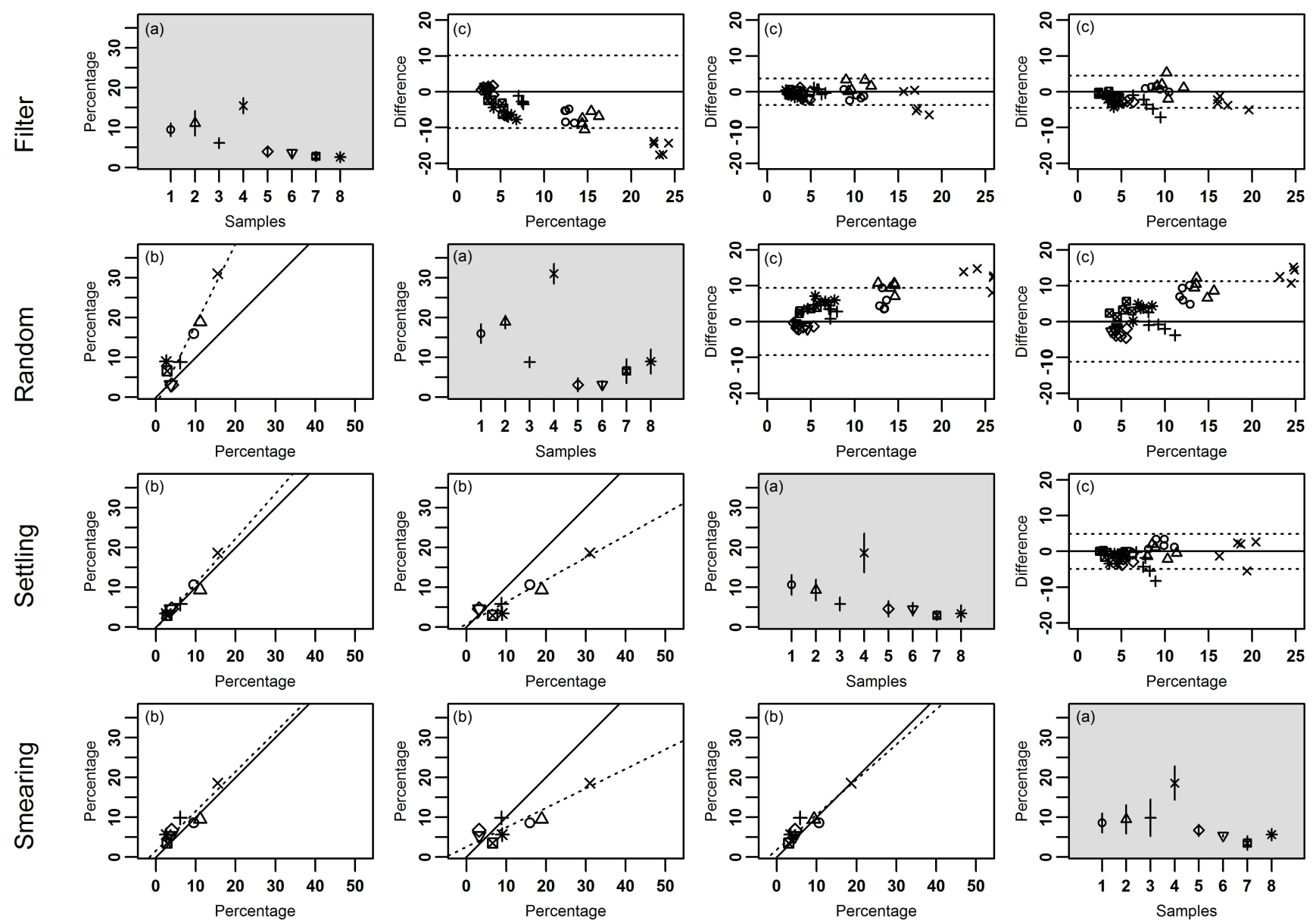

Filter

Random

Settling

Smearing 
Fig. 3 - Lupi et al. (2 columns)
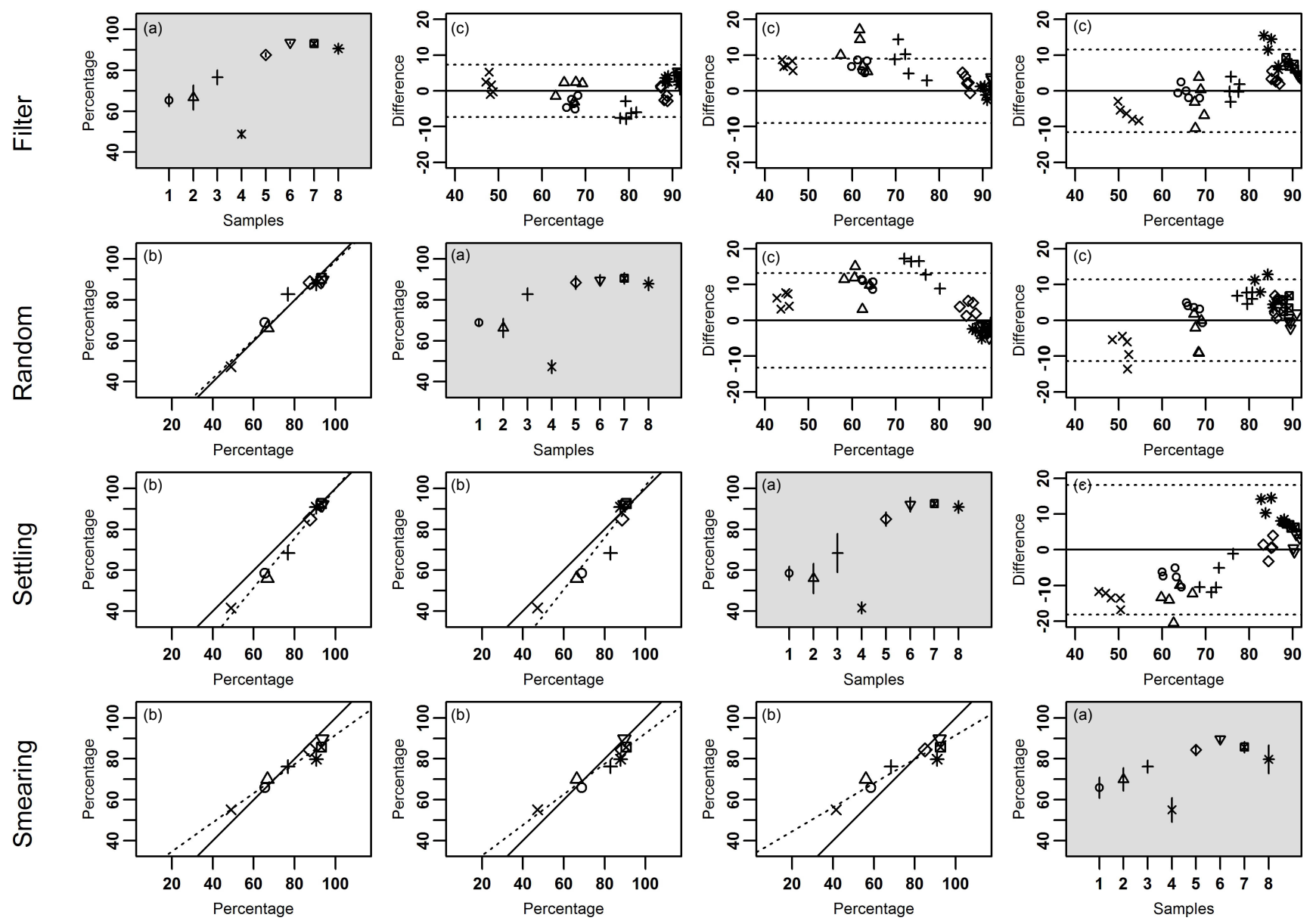

Filter

Random

Settling

Smearing 
Fig. 4 - Lupi et al. (2 columns)

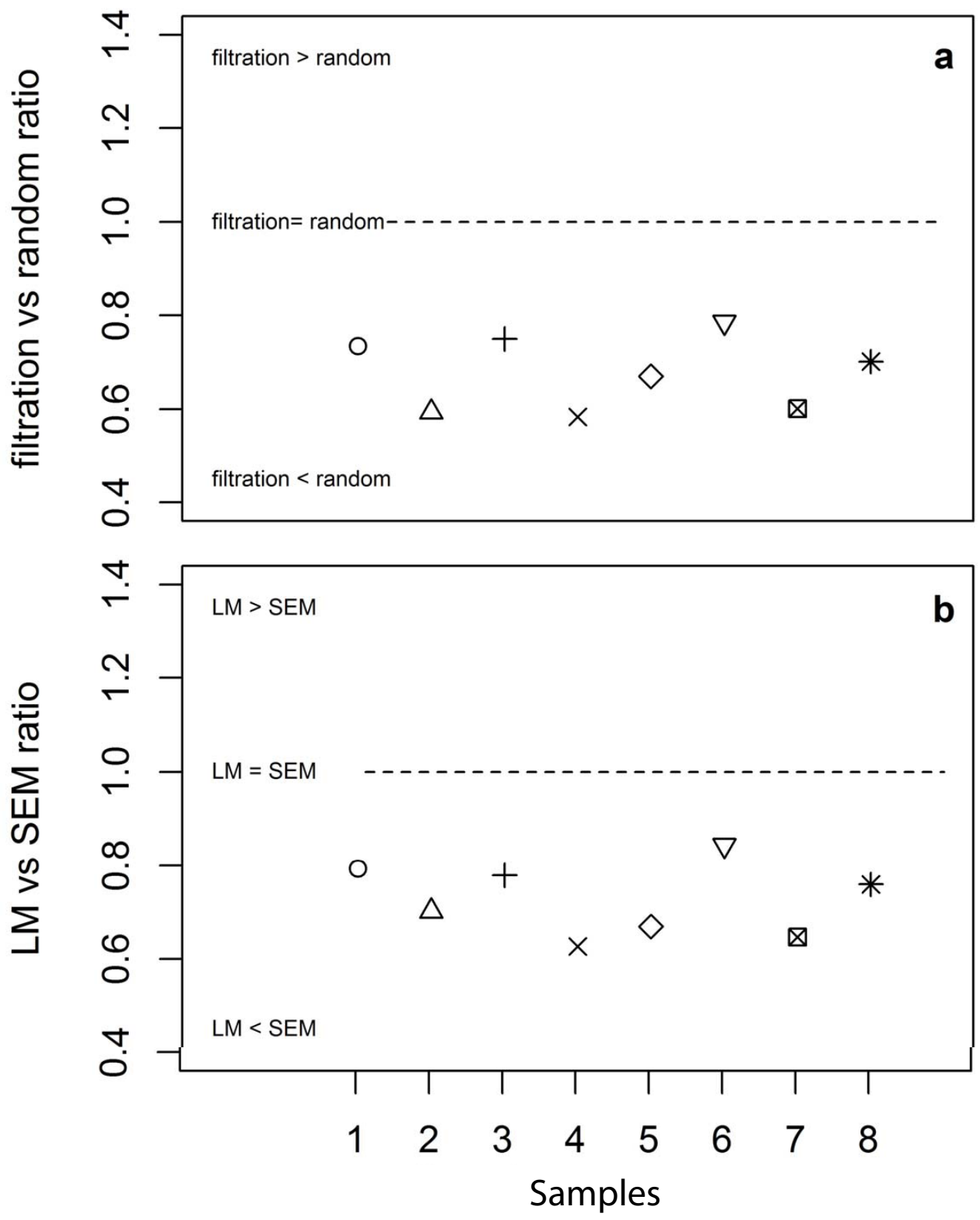


Fig. 5 - Lupi et al. - 2 columns

a
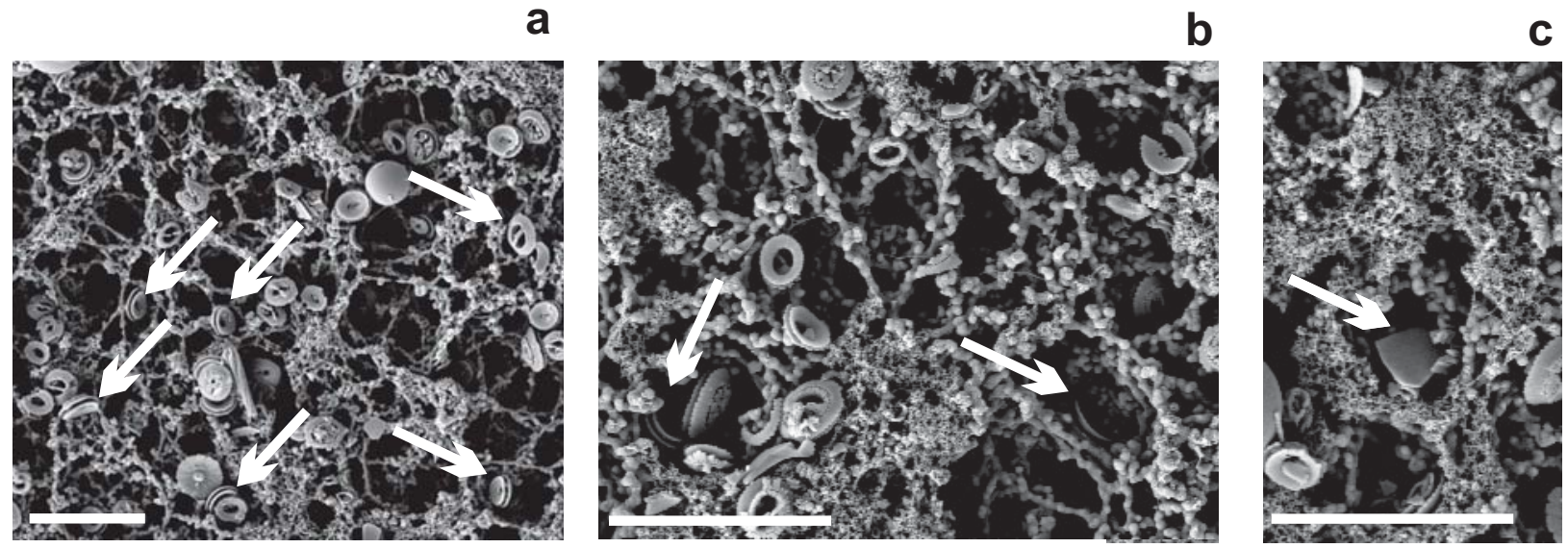

C 